\title{
Sexual initiation and contraceptive use among female adolescents in Kenya
}

\author{
Lawrence D.E. Ikamari and Rose Towett \\ Population Studies and Research Institute, University of Nairobi P. O. Box 30197-00100 \\ Fax \#254020245566 Nairobi Kenya, likamari@uonbi.ac.ke
}

\begin{abstract}
SUMMARY
This paper examines the timing of sexual initiation and contraceptive use among female adolescents in Kenya. Data are drawn from the 2003 Kenya Demographic and Health Survey. The main analytical tools are regression models. A Cox regression model is used to consider the probability of a young woman having first sex during adolescence and linear regression model to quantify the effects of a set of factors on female adolescent's age at first sexual debut. Finally, logistic regression model is used to model the probability of a sexually experienced adolescent woman using a contraceptive method. The results obtained indicate the onset of sexual activity is early and contraceptive use is fairly low and both the timing of first sex and contraceptive use are affected by a variety of factors. Despite engaging in unsafe sex practices, the majority of the adolescents do not view themselves as being at the risk of contracting HIV/AIDS. A number of recommendations are proposed.
\end{abstract}

[Afr J Health Sci. 2007; 14:1-13]

\section{Introduction}

Kenya is one of the countries in Sub-Saharan Africa that have high levels of adult and adolescent childbearing and HIV/AIDS infection. The risk of unplanned pregnancy and sexually transmitted infections (STIs) including HIV/AIDS may be affected by the age of sexual debut. Sexual activity at younger ages may be associated with greater likelihood of unprotected intercourse and multiple partners, potentially leaving the adolescent at greater risk of contracting an STI/HIV/AIDS [12].

Early initiation of sexual activity prolongs the period of exposure to risk of pregnancy during the reproductive span. It often leads to early marriage and child bearing [34]. Early child bearing is fraught with substantial health risks for both the mother and the child. Young mothers are more likely to experience pregnancy related complications and less able to deal with them, which often lead to maternal death [5]. Children born to young mothers are usually subject to elevated risks of morbidity and mortality $[5,6]$. Furthermore, early motherhood tends to impede the pursuit of other life options such as formal schooling and career development that might compete with childbearing [7- 11]. Due to the fact that early childbearing hinders a mother's educational attainment, it often results in reducing economic opportunity for the mother and the household as a whole. The above mentioned serious health risks of early sexual activity and child bearing underlie the need for addressing adolescent sexual and reproductive health.

\section{Theoretical paradigms}

In the literature two main theoretical paradigms have been used to explain sexual activity among adolescents in transitional societies. These are the social disorganization model and rational adaptation model. The social disorganization model observes that, adolescent's sexual behaviour is seen as a result of a breakdown of social control over young adults by their elders and the rise of behaviour oriented toward personal satisfaction and emotional gratification rather than family responsibility [12].

The process of urbanization and the increasing influences of western cultural precepts on many population groups, but especially the young, are seen to be responsible for the breakdown of traditional customs. In this sense, the increase in premarital sexuality and the increase in unmarried teenage pregnancy are seen by many authors as a consequence of the introduction of "western" values and ways of conduct, which expand more easily in the urban context and through the media available in this context. In Botswana, for example, until about 30 years ago, traditional teachings and social practices including strict gender segregation for certain activities, taboos, and a universal social disapproval of teenage pregnancy, made it a very rare phenomenon. Urbanization and detribalization have 
loosened those social practices, and in the process sexual activity among youths has become more prevalent and unmarried teenage pregnancy more frequent [13 14].

In the process of urbanization, two factors are especially relevant in the changes in sexual practices and outcomes: education and the changes in the traditional systems of social controls. With urbanization the socialization processes shifts from being entirely the responsibility of the direct or extended family to being partially dominated by social institutions like the school, under the ever stronger influence of the media. The introduction of western values often destroys traditional customs, traditions and value systems. In the process and as a consequence, other forms of social control lose relevance, as the weight of western values, attractive to the young, cannot be countered by local propositions [15].

This type of explanation argues that most early sexual activity is unplanned and most premarital pregnancies are unwanted. It stresses the influence of the mass media, the peer group, the school, social welfare programs, and other institutions that allegedly weaken family control, as well as the weakening effects of poverty and unemployment. This model is consistent with modernization theory that emphasizes the decline of traditional structures of social control and the rise of individualism [16].

On the other hand, according to the rational adaptation model young women exchange sexual favours for clothes, gifts, or school fees, while others may seek to become pregnant as a way of proving their fecundity and their fitness for marriage, or to obtain financial support outside of sexual debut. These motivations for sexual activity suggest that becoming sexually active may be a rational decision, based on a weighing of benefits (such as school fees, the opportunity to find a husband, or the acquisition of needed goods and services) versus costs (pregnancy and expulsion from school, the risks of abortion, abandonment by a potential husband).

Recent studies have documented the phenomenon of "sugar daddies" (older men offering gifts of cash or kind to young unmarried women in exchange for sexual favours) [ [lll 18 19]. Some scholars have indicated that economic transactions following intercourse are frequent among both adolescent men and women in many countries of subSaharan Africa, and are not necessarily perceived as a source of social condemnation [ [17 18 19]. Reciprocity of the giving and receiving between girls and boys is common, and characterise a majority of early sexual encounters in some areas. However, some recent studies have also indicated that some of the sexual episodes among adolescent women are involuntary as coercion is used [ [20 212223$]$.

In the Kenyan context, little is known about the effects of factors such as education on an adolescent woman's age at first sexual initiation and contraceptive behaviour and as such they are poorly understood. This study is, therefore, aiming at establishing the effects of some of the factors that have been indicated in the literature to be closely associated with the adolescent woman's age at first sex elsewhere [ [ll 24262728 29]. In particular, the study examines the effects of educational attainment, urbanization, household economic status, region of residence, religion and exposure to mass media on an adolescent woman's age at first sex and use of contraception. The paper also seeks to examine the 'sugar daddy' phenomenon by considering the age of sexual partners and whether or not economic transactions characterize adolescent sexual encounters.

\section{Source of data}

The data for this study is drawn from the 2003 Kenya Demographic and Health Survey (KDHS). The KDHS was conducted to collect data on fertility, marriage, sexual activity, fertility preferences, family planning, maternal and child health, information about HIV/AIDS and other sexually transmitted diseases, information on malaria and use of mosquito nets and domestic violence. The survey was carried out as part of the world- wide DHS program. The survey covered a national representative sample of 8,195 women aged 15-49 years selected from 400 sample points (clusters) throughout the country. The Survey used a two-stage sample based on the 1999 Population and Housing Census and was designed to produce separate estimates for key indicators for each of the eight provinces in Kenya [11].

This study focuses on 3453 adolescent women aged 15-24 years who include both single and ever- married women and the unit of analysis are individual adolescent women.

\section{Description of the explanatory variables}

This study considers region of residence, urbanization, exposure to mass media, household economic status, and religion. The education variable refers to the highest level of education attained by adolescent as the time of the survey. This is measured in terms of no education, primary, and at least secondary education.

Region of residence refers to the region in which the adolescent usually resides. There are eight provinces in Kenya. These regions differ significantly in terms of socio-economic development, geography 
and culture. Generally, due to historical and political reasons, Nairobi, Central and some parts of the Rift Valley province are more economically developed than the other provinces located at the periphery of the Capital City of Nairobi which is the seat of government.

Furthermore, there are discernible regional cultural variations in Kenya, as one or two ethnic groups predominantly inhabit each of the eight regions. For example, Central Province is predominantly inhabited by the Kikuyu, Coast Province by the Mijekenda, Nyanza by the Luo and Kisii, Western Province by the Luhya, Eastern by Kamba, Embu and Meru, Rift Valley by the Kalenjin, North Eastern by the Somali and Boran, while Nairobi Province is metropolitan. Each ethnic group has its own socio-cultural ideologies about sexuality and reproduction. These ideologies are composed of the norms, beliefs and values as well as the practices that are likely to affect positively or negatively the reproductive performance of a given society. It is likely that each cultural group may stress certain aspects in their reproductive institutions. These group norms, ideals and beliefs have been used to explain ethnic variation in the timing of marriage and childbearing [ [ $\left.\begin{array}{llll}30 & 31 & 32 & 33\end{array}\right]$. We would expect significant variation in the age at first sex and contraceptive use across the regions of Kenya due to the socio-economic and cultural differences. This is a nominal variable with eight categories, representing the eight provinces (See Table 1).

The type of place of usual residence and childhood place of residence represent urbanisation. Generally, rural areas are generally associated with early marriage and childbearing. People living in urban areas are exposed to a more diverse life style and subject to a weaker social control than those in rural areas. Rural areas tend to have institutional and normative structures such as the kinship and extended family that promote early marriage and childbearing [34]. These social structures and networks are less potent and individual responsibility in matters of sex and family formation is emphasized in urban areas. People in urban areas have more exposure to information on sexuality, reproduction, HIV/AIDS and contraception and have a greater access to reproductive health services including contraceptives. In Kenya, as in other developing countries, urban areas usually have the largest share of the country's well-educated, high income population and the best educational and health facilities [35]. Thus, urban areas are expected to be associated with later sexual initiation and higher probability of contraceptive use among the sexually experienced adolescent women. This is a dichotomous variable, denoting rural or urban residence.
With regard to exposure to mass media, we consider in this analysis radio listenership as representative of exposure to mass media and new ideas. Listening to the radio can occur wherever a female adolescent is, including outside of her usual household and, therefore, is considered less associated with economic status and radio ownership. This is measured in terms of whether the adolescent listens to a radio every day or at least once a week or less than once a week or not at all.

Household economic index is used to measure the household economic status. The DHS program has created as a household economic index variable using household asset data with principal components analysis. The information used included ownership of a number of consumer items ranging from a television to a bicycle or a car, as well as dwelling characteristics, such as source of drinking water, sanitation facilities, and type of material used for flooring. Each asset was assigned a weight generated through principal components analysis, and the resulting asset scores were standardised in relation to a normal distribution with a mean of zero and a standard deviation of one. Each household was then assigned a score for each asset and the scores were summed for each household; individuals were ranked according to the total score of the household in which they resided. The scores were ranked in terms of quintiles from one (lowest) to five (highest) [11]. In this study, the lowest and second quintiles constitute poor households and the third, fourth and fifth quintiles the well- to-do households.

Finally, this study will also examine the effect of religion on the adolescent woman's age at first sex and use of contraception. There are several religions and Kenyans are generally religious. The main denominations are Catholic, Protestant and Muslim. Religious norms and beliefs affect one's orientation towards sexuality and reproduction, among other things; thus, religion is bound to affect a woman's age at first sex and her contraceptive behaviour.

\section{Methods of data analysis}

The main dependent variable is the age at first sexual debut measured in terms of completed years. During the Survey all women were asked a series of questions regarding their sexual activity. All women who were sexually experienced were asked to indicate how old they were when they first had sexual intercourse. The response to this question constitutes the woman's age at first sexual debut. All the women who indicated that they had never had sexual intercourse were not asked the question about the age at first sexual debut. This is the standard way in 
which age at first sexual debut is being measured in the worldwide DHS program. The other dependent variable of interest in this paper is the ever-use of any contraceptive method by the sexually experienced adolescents either during the first sex and /or subsequent sexual encounters.

The age at first sexual debut may be interpreted as survival time from a virgin state to a non- virgin state. Throughout this interval, women may either change state into a non- virgin or be right censored at the time of the survey. In this case, women who were virgins at the time of the survey constitute censored cases. Censored cases require special treatment in estimating exposure time, and as such, ordinary regression procedures are not appropriate. We, therefore use continuous time event history analysis techniques [36]. In particular, the general proportional hazard (Cox) model is used to assess the covariates on the timing of first sexual debut among the study population. In this paper, the coefficients of the covariates will be transformed by exponentiation and interpreted as risk ratios.

We present the results as risk ratios, which represent the relative likelihood of a female adolescent with the specific characteristic of having sex intercourse in comparison to a female adolescent who would be in the appropriate reference group. The risk ratio of the reference group or category is one (1.00). If the risk ratio of a given category is greater than 1.00, this indicates greater risk of having sexual intercourse, and when the risk ratio is less than 1.00, it indicates a lower risk of having sexual intercourse compared to the reference group. In this analysis, a variable will be reported as having a significant effect, if its effect on the age at first sex is statistically significant at least at the 5 per cent level of significance.

In an effort to further quantify the effects of selected explanatory variables on the adolescent's age at first sex, separate analyses are carried out among the sexually experienced adolescents. In these analyses linear regression analysis is used and the dependent variable is age at first sex as reported by the sexually experienced adolescents during the survey. Finally, a logistic regression model is used to model the probability of a sexually experienced adolescent using a contraceptive method.

\section{Results}

\section{Results based on all adolescents}

Analysis using descriptive statistics revealed that 61.7 per cent of the 3454 adolescents aged 15-24 years were already sexually experienced as at the time of the survey. By the age of 19 years, 30 per cent of all the adolescents had already initiated sexual activity. In Figure 1, we further explored the association between age and sexual initiation using the cumulative percentage of adolescents who were already sexually experienced at a specified age.

\section{Results of multivariate analysis}

The results obtained by fitting the Cox model using all the adolescents aged 15-24 are presented in Table 2. Model I presents the results with education as the only explanatory variable. Model II has only three explanatory variables: education, age and marital status of the adolescent. And Model III includes all the explanatory variables. The results in Models II and III indicate that education has a significant effect on the timing of first sex: adolescent with at least secondary education are more likely than those with no education to initiate sexual activity late. The effect of education is largely independent of all the other explanatory variables included in Model III. In both Model II and III the respective effects of age and marital status are also statistically significant. As expected, older adolescents and ever-married adolescents are more likely than the young and single adolescents to initiate sexual activity early. For instance, the ever-married adolescents are almost 5 times more likely than single adolescent to initiate sexual activity early.

Unexpectedly, rural adolescents are indicated as less likely than urban adolescents to initiate sexual activity. They are almost 14 percent less likely (Model III). This result is unexpected because usually rural areas are associated with traditional practices that encouraged early onset of sexual activity and marriage [34].

Regional variation in the timing of first sex is evident in Model III. Compared to adolescents in Nairobi province, adolescents in Nyanza and Western provinces are significantly more likely to initiate sexual activity early. For example, adolescents in Nyanza province are 1.56 times as likely as adolescents in Nairobi province to initiate sexual activity early. Adolescents in North Eastern are significantly less likely than adolescents in Nairobi province to initiate sexual activity early. Adolescents in all other provinces are showed not to be statistically different from those in Nairobi provinces in terms of their timing of first sex.

Household economic status and listenership to a radio have each no statistically significant effect on the timing of first sex among the adolescents. Religion is weakly associated with the timing of first sex. Muslim adolescents are significantly less likely than Catholic adolescents to initiate sexual activity early. The timing of first sex between the Protestant and other non-Catholic Christian adolescents are 
significantly different from that of the Catholic adolescents.

Table 1: Percent distribution of the study population according to the covariates: Kenya, 2003

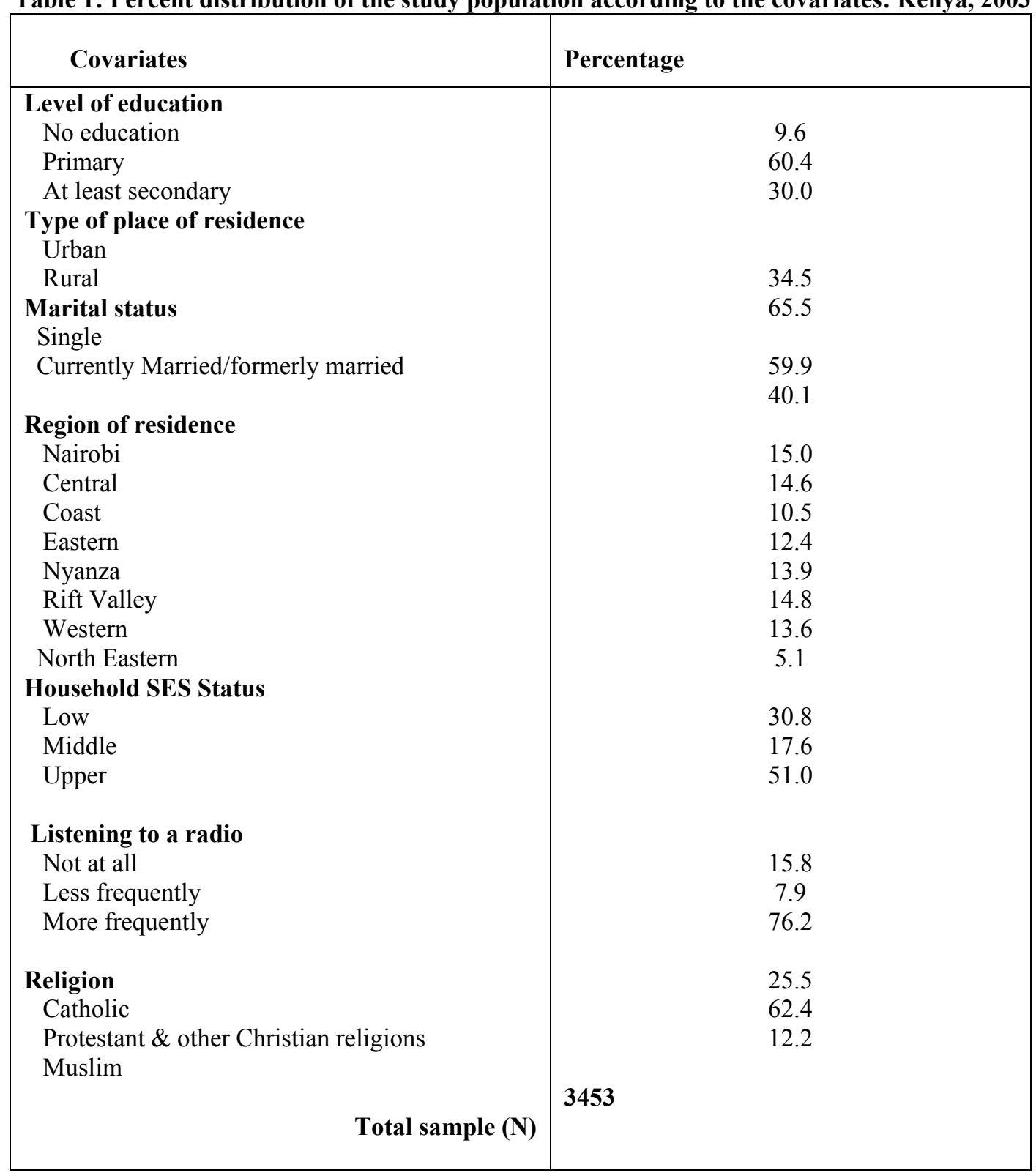

Source: Primary Analysis of the 2003 KDHS data.

\section{Analysis based on sexually experienced adolescents}

\section{Results of bivariate analysis}

Figure 2 presents the distribution of the 2132 sexually experienced adolescents according to how old they were when they first had sex. The mean age at first sex is 16.2 , with a mode of 15 years and with the median age at first sex being 16 years. The onset of sexual activity is fairly early; 4 of the 2132 adolescents had their first sexual debut when they were just 8 years of age. By age 16, 56 per cent of the adolescents were already sexually experienced and by age 18,84 per cent of them had already had their first sex. And by age 20 nearly of $97 \%$ of them were 
sexually experienced. The majority of the sexually experienced adolescents were fairly sexually active; with nearly half of them indicating that they had a sexual activity the month preceding the survey. These results are in conformity with those found in earlier studies in Kenya [ [ 537 38] and in some other African countries [ $\left[\begin{array}{llll}18 & 26 & 29 & 39\end{array}\right]$. The majority (54\%) of the adolescents had their first sex with an older partner; $44.3 \%$ of them had a partner who was older by less than ten years and $9.8 \%$ had a partner who was at least ten years older. About 43 per cent of the adolescents had their first sex with a partner who was about their age and a very small percentage $(0.8 \%)$ had a younger partner. These results suggest that young women seem to prefer partners who are older than themselves to those who are younger than them. During the survey all the sexually experienced respondents were asked whether they had given or received money or gift or favours in return for sex. Only 1752 out of the 2132 adolescents responded to the question. The majority of them $(91.3 \%)$ reported that had never given or received money or gift or favours in exchange for sex. However, 8.7 percent of them indicated that indeed they did give or receive money/gift/favour in return for sex. These results suggest that financial transactions do not characterise much of the sexual activity among the adolescents.

Figure 1: The cumulative percentage of female adolescents who are already sexually experienced by a specified age

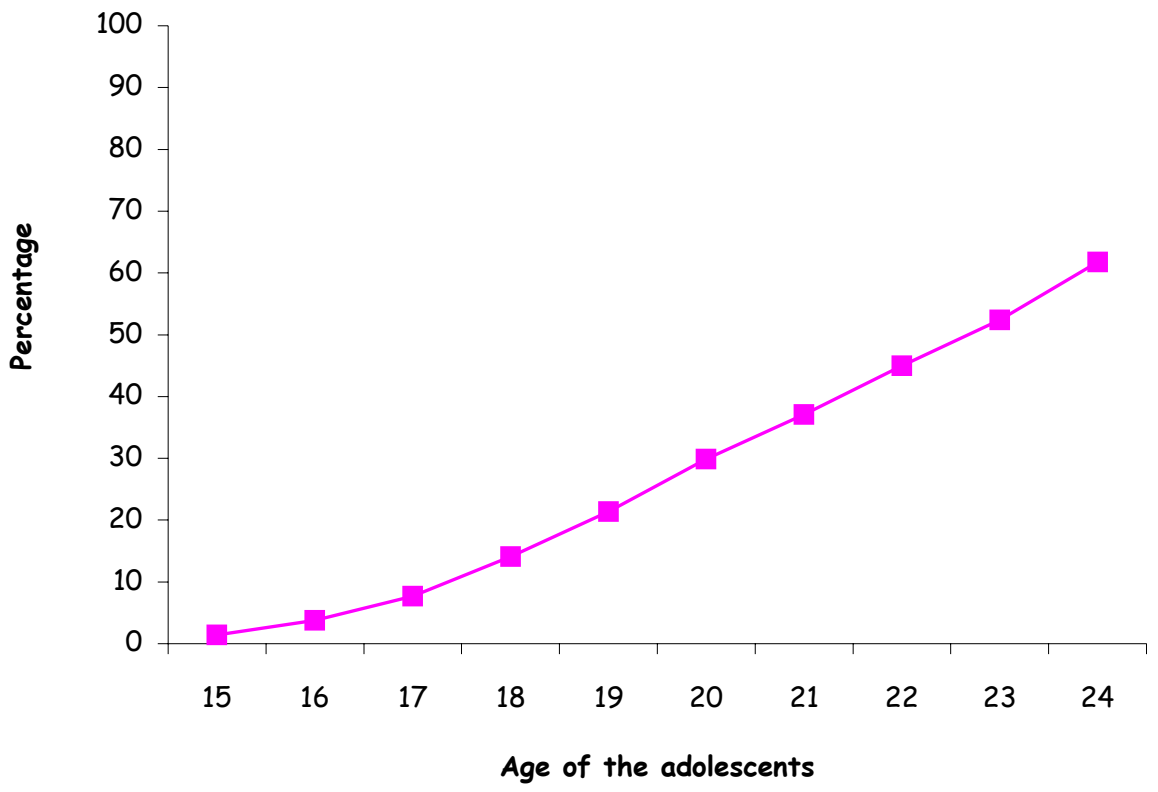

\section{Results of multivariate analysis}

Table 3 present the results of linear regression analysis with the age at first sex as a dependent variable. These results indicate most of the explanatory variables have modest effects on the age at first sex among the study population. For instance at least secondary education delays the onset of sexual activity by about eight months on the average (Model III). Adolescents with primary education are more likely than those with no education to initiate sexual activity; on the average they initiate sexual activity six months earlier. Education, age, marital status, type of place of residence, region of residence and listenership to a radio have each a significant effect on age at first sex. However, the respective effects of type of place of residence and listenership to a radio are rather weak. Household economic status and religion have each insignificant effect on age at first age. The entire eight explanatory explain 21.1 per cent of the variation in age at first sex. 
Table 2: A Hazard Model of the risk of first sex debut among female adolescents aged 15-24 years: Kenya, 2003

\begin{tabular}{|c|c|c|c|}
\hline Covariates & Model I & Model II & Model III \\
\hline \multicolumn{4}{|l|}{ Level of education } \\
\hline No education & 1.00 & 1.00 & 1.00 \\
\hline Primary & 0.91 & 1.09 & $0.69 *$ \\
\hline At least secondary & $0.56 * * *$ & $0.76^{*}$ & $0.47 * * *$ \\
\hline \multicolumn{4}{|l|}{ Age } \\
\hline $15-19$ & & 1.00 & 1.00 \\
\hline $20-24$ & & $1.19 * *$ & $1.19 * *$ \\
\hline \multicolumn{4}{|l|}{ Marital status } \\
\hline Single & & 1.00 & 1.00 \\
\hline Currently/formerly married & & $4.86 * * *$ & $4.85 * * *$ \\
\hline \multicolumn{4}{|l|}{ Type of place of residence } \\
\hline Urban & & & 1.00 \\
\hline Rural & & & $0.86^{*}$ \\
\hline \multicolumn{4}{|l|}{ Region of residence } \\
\hline Nairobi & & & 1.00 \\
\hline Central & & & 0.97 \\
\hline Coast & & & 0.94 \\
\hline Eastern & & & 1.09 \\
\hline Nyanza & & & $1.58 * * *$ \\
\hline Rift Valley & & & 0.98 \\
\hline Western & & & $1.15^{*}$ \\
\hline North Eastern & & & $0.69 * *$ \\
\hline \multicolumn{4}{|l|}{ Household SES } \\
\hline Low & & & 1.00 \\
\hline Middle & & & 1.12 \\
\hline Upper & & & 1.10 \\
\hline \multicolumn{4}{|l|}{ Listening to a radio } \\
\hline Not at all & & & 1.00 \\
\hline Less than once a week & & & 0.97 \\
\hline More frequently & & & 0.93 \\
\hline \multicolumn{4}{|l|}{ Religion } \\
\hline Catholic & & & 1.00 \\
\hline Protestant \& other Christian religions & & & 0.94 \\
\hline Muslim & & & $0.76^{*}$ \\
\hline
\end{tabular}

Notes: Significance: $* * * \mathrm{p}<0.000, * * \mathrm{p}<0.01, * \mathrm{p}<0.05$.

Source: Primary Analysis of the 2003 KDHS data

\section{Contraceptive use}

\section{Results of bivariate analysis}

The ever use of contraception among the sexually experienced adolescent is fairly high. 46.9 per cent of them have ever used a contraceptive with 37.7 per cent of them reporting ever use of modern contraceptives. However, only about 13 per cent of them used a condom during their first sex. These indicate that most of them had unsafe sex.

Current use of contraceptives among the adolescents is fairly low; only 21.5 percent of them reported current use of contraceptives with 9.2 per cent of them on injection, 3.9 per cent practising period abstinence, 3.8 percent on the pill and 2.8 per cent reporting the use of condoms and 1.8 per cent use other methods. These results indicate low usage of condoms among the adolescents yet condoms offer protection against unwanted pregnancy as well as sexually transmitted infections, including HIV/AIDs.

When asked to assess their chances of getting HIV/AIDs, 33.5 per cent of all the sexually experienced adolescents reported that they were not at risk at all, 42.9 percent indicated small risk, 14.7 per cent moderate risk and only 8.9 percent of them reported being at a great risk of contracting HIV/AIDS. The majority $(69.3 \%)$ of the adolescents who reported being at no or small risk indicated that they had only one partner and 18.6 per cent of them indicated that they were abstaining from sex and 
about 5 per cent of them gave use of condoms as the reason for perceiving themselves being at low or small risk. While those indicating moderate/ great risk reported that their partners had more that one partner $(62.1 \%)$, not using condoms $(22.2 \%)$, have more than one partner $(12 \%)$ as the basis for their perception. These results indicate that despite low use of condoms the majority of the sexually experienced adolescents do not perceive themselves as being at a great risk of contracting HIV/AIDS reason being that they had only one partner.

Figure 2: Distribution of the 2132 adolescents by age at first sex

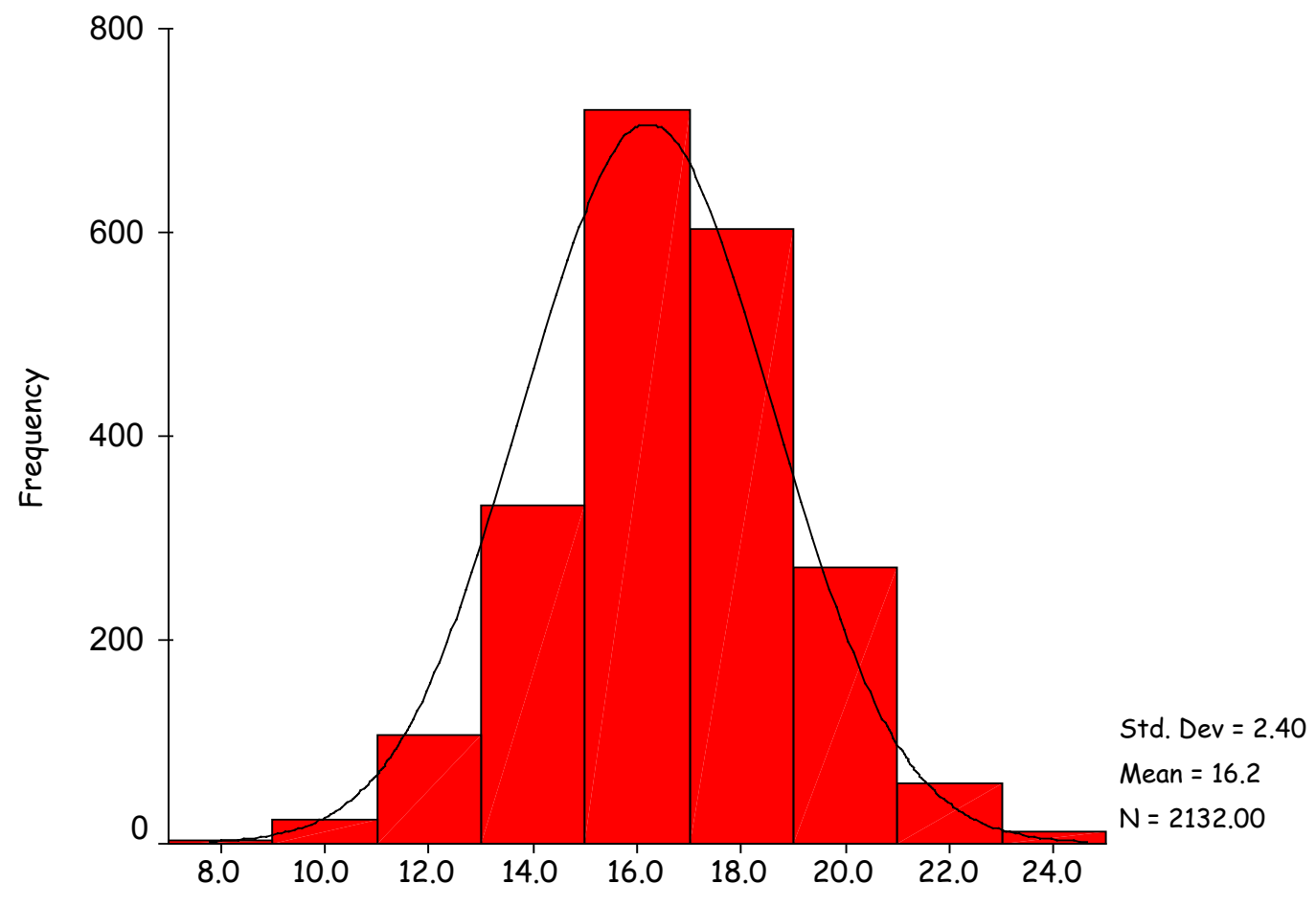

Age at first sex in single years

\section{Results of multivariate analysis}

In Table 4 are the results of logistic regression on ever use of contraception by the sexually experienced adolescents. Model III show that all the explanatory variables except for the type of place of residence and religion have each a statistical significant effect on ever - use of contraception. Use of contraception increased with the level of education and age of the adolescent. Ever married adolescent were twice are likely as the single adolescents to use contraception. Significant regional variation in the use of contraception among the adolescent is apparent. Adolescents in Central province, Eastern and Western province were significantly more likely than hose in Nairobi province to use contraception. However, adolescents in North Eastern, Nyanza and Coast province were significantly less likely than adolescent in Nairobi province to use contraception.

Household economic status was closely associated with ever-use of contraception. Adolescents in middle and upper class households were significantly more likely to use contraception compared to their counterparts in low class or poor households. Similarly, adolescents who ever listened to a radio were significantly more likely than those who never listened to a radio to use contraception. And those who listened more frequently were even more likely to use contraception. 
Table 3: Linear regression analysis results of explanatory variables on age at first sex among female adolescents aged 15-24 years: Kenya, 2003 KDHS

\begin{tabular}{|c|c|c|c|}
\hline Explanatory variable & Model I & Model II & Model III \\
\hline \multicolumn{4}{|l|}{ Level of education } \\
\hline No education & 0.00 & 0.00 & 0.00 \\
\hline Primary & $-0.60 * * *$ & $-0.49 * * *$ & $-0.35 *$ \\
\hline At least secondary & $0.97 * * *$ & $0.73 * * *$ & $0.78 * *$ \\
\hline \multicolumn{4}{|l|}{ Age } \\
\hline $15-19$ & & 0.00 & 0.00 \\
\hline $20-24$ & & $1.72 * * *$ & $1.62 * * *$ \\
\hline \multicolumn{4}{|l|}{ Marital status } \\
\hline Single & & 0.00 & 0.00 \\
\hline Currently/formerly married & & $-0.50 * * *$ & $-0.42 * * *$ \\
\hline \multicolumn{4}{|l|}{ Type of place of residence } \\
\hline Urban & & & 0.00 \\
\hline Rural & & & $0.203 *$ \\
\hline \multicolumn{4}{|l|}{ Region of residence } \\
\hline Nairobi & & & 0.00 \\
\hline Central & & & $-0.55^{* *}$ \\
\hline Coast & & & -0.55 \\
\hline Eastern & & & $-0.92 * * *$ \\
\hline Nyanza & & & $-1.30 * * *$ \\
\hline Rift Valley & & & $-0.55 * *$ \\
\hline Western & & & $-0.86 * *$ \\
\hline North Eastern & & & 0.24 \\
\hline \multicolumn{4}{|l|}{ Household SES } \\
\hline Low & & & 0.00 \\
\hline Middle & & & 0.16 \\
\hline Upper & & & 0.36 \\
\hline \multicolumn{4}{|l|}{ Listening to a radio } \\
\hline Not at all & & & 0.00 \\
\hline Less than once a week & & & $-0.36^{*}$ \\
\hline More frequently & & & -0.11 \\
\hline \multicolumn{4}{|l|}{ Religion } \\
\hline Catholic & & & 0.00 \\
\hline Protestant \& other Christian religions & & & -0.01 \\
\hline Muslim & & & -0.19 \\
\hline Constant & 16.37 & 15.55 & 15.87 \\
\hline
\end{tabular}

Notes: Significance: $* * * p<0.000, * * p<0.01, *$ Source: Primary Analysis of the 2003 KDHS data $\mathrm{p}<0.05$.

\section{Discussion}

This study set out to establish the effect of some factors on adolescent's woman age at sexual initiation and contraceptive behaviour using data from the 2003 KDHS. The paper also sought to examine the 'sugar daddy' phenomenon, and whether or not economic transactions characterised most sexual encounters.

The results obtained show that the majority $(62 \%)$ of Kenyan adolescents are sexually experienced. The mean age at first sex is 16.2 , with a mode of 15 years and with the median age at first sex being 16 years. The onset of sexual activity is fairly early; 4 of the 2132 sexually adolescents had their first sexual debut when they were just 8 years of age. The majority of the sexually experienced adolescents were fairly sexually active; with nearly half of them indicating that they had a sexual activity the month preceding the survey. These results are in conformity with those found in earlier studies in Kenya [ 53738 3

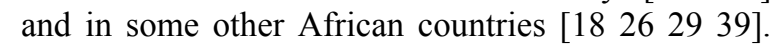
These results obtained suggest that young women seem to prefer sexual partners who are older than 
themselves to those who are younger than them. The majority of them of the sexually experienced adolescents reported that they had never given or received money or gift or favours in exchange for sex. These results suggest that financial transactions do not characterise much of the sexual activity among the adolescents.

The results also show that most of them engage in risky sexual behaviour as depicted by the low use of condoms, which would otherwise protect them from unwanted pregnancies and sexually transmitted infections, including HIV/AIDS. Surprisingly, few of them thought they were at risk of the HIV/AIDS despite the low usage of condoms. Financial transactions were found not to characterise most sexual activity among the adolescents.

The results of multivariate analysis showed that sexual initiation and contraceptive behaviour varied by a number of selected characteristics. For instance, education was found to be positively associated with the timing of first sex and contraceptive use. Secondary education, for instance delays the onset of sexual activity by about eight months. Use of contraception and sexual initiation increased with the adolescent's age. Being ever married is positively associated with both early sexual initiation and contraceptive use. The results do not support the hypothesis that adolescents in urban areas are less likely to initiate sexual activity early compared to those in rural areas. In fact, adolescents in rural areas are $14 \%$ less likely than their urban counterparts to initiate sexual activity early. Though adolescents in rural areas are less likely to use contraception than their urban counterparts, this result is insignificant. As expected regional variation exist in sexual initiation and contraceptive use among female adolescents in Kenya. Adolescents in Nyanza and Western provinces are significantly more likely to initiate sexual activity early, while those in North Eastern province are less likely, compared to those in Nairobi. On the other hand, adolescents in Central, Eastern and Western provinces were significantly more likely to use contraception, while those in North Eastern, Nyanza and Coast provinces were significantly less likely to use contraception, compared to those in Nairobi province. Adolescent reproductive health programmes should be strengthened throughout the country. More emphasis should be given to provinces such as, North Eastern, Nyanza and Coast province since the adolescents these areas initiate sexual activity early, and are less likely to use contraceptives.

Although household economic status and radio listener ship has no statistically significant effect on the risk of first sex, it is significantly associated with the use of contraception. This has important policy implications: since contraceptive use among adolescents in poor households is low, concerted efforts should be made to increase the availability of affordable of contraceptive is use should be strengthened among them, especially using the mass media. Appropriate radio programmes targeting the adolescents to increase awareness of adolescent reproductive health and rights and to promote contraceptive use should be set up countrywide since increased radio listenership encourages contraceptive use.

\section{Conclusion}

In conclusion, these results imply the need to intensify efforts to inform and educate adolescents about responsible and healthy attitudes towards sexuality, the need to delay the onset of sexual activity and to decrease risky sexual practices. They adolescents and young children should be targeted with the appropriate information when they are still fairly young, for example, when they are still in primary level of education. Similarly, efforts should be intensified to encourage the sexually experienced adolescents to have access to and use contraceptives including condoms for the prevention of both STI/HIV/AIDS and unwanted pregnancy. 
Table 4: Logistic regression analysis results on use of contraception among 2132 sexually experienced female adolescents aged 15-24 years: Kenya, 2003 KDHS

\begin{tabular}{|c|c|c|c|c|}
\hline Covariates & $\begin{array}{l}\text { No. of } \\
\text { cases }\end{array}$ & Model I & Model II & Model III \\
\hline \multicolumn{5}{|l|}{ Level of education } \\
\hline No education & 225 & 1.00 & 1.00 & 1.00 \\
\hline Primary & 357 & $6.49 * * *$ & $7.76^{* * *}$ & $2.75 * * *$ \\
\hline At least complete secondary & 550 & $13.20 * * *$ & $16.2 * * *$ & $5.48 * * *$ \\
\hline \multicolumn{5}{|l|}{ Age } \\
\hline $15-19$ & 739 & & 1.00 & 1.00 \\
\hline $20-24$ & 1393 & & $1.84 * * *$ & $1.69 * * *$ \\
\hline \multicolumn{5}{|l|}{ Marital status } \\
\hline Single & 755 & & 1.00 & 1.00 \\
\hline Currently/formerly married & 1377 & & $1.68 * * *$ & $2.00 * * *$ \\
\hline \multicolumn{5}{|l|}{ Type of place of residence } \\
\hline Urban & 755 & & & 1.00 \\
\hline Rural & 1377 & & & 0.87 \\
\hline \multicolumn{5}{|l|}{ Region of residence } \\
\hline Nairobi & 327 & & & 1.00 \\
\hline Central & 269 & & & $2.57 * * *$ \\
\hline Coast & 210 & & & $0.79 *$ \\
\hline Eastern & 262 & & & $1.75^{* * *}$ \\
\hline Nyanza & 354 & & & $0.68 * *$ \\
\hline Rift Valley & 325 & & & 1.12 \\
\hline Western & 285 & & & $1.61 * * *$ \\
\hline North Eastern & 100 & & & $0.05 * * *$ \\
\hline \multicolumn{5}{|l|}{ Household SES } \\
\hline Low & 679 & & & 1.00 \\
\hline Middle & 372 & & & $1.36^{* *}$ \\
\hline Upper & 1081 & & & $1.71 * * *$ \\
\hline \multicolumn{5}{|l|}{ Listenership to a radio } \\
\hline Not at all & 317 & & & 1.00 \\
\hline Less than once a week & 357 & & & $1.51 * * *$ \\
\hline More frequently & 1458 & & & $1.56 * * *$ \\
\hline \multicolumn{5}{|l|}{ Religion } \\
\hline Catholic & 554 & & & 1.00 \\
\hline Protestant \& other Christians & 1329 & & & 0.98 \\
\hline Muslim & 249 & & & $0.77 *$ \\
\hline
\end{tabular}

Notes: Significance: $* * * \mathrm{p}<0.000,{ }^{* *} \mathrm{p}<0.01,{ }^{*} \mathrm{p}<0.05$.

Source: Primary Analysis of the 2003 KDHS data

\section{References}

1. Blanc, A and Way A. Sexual Behaviour and Contraceptive Knowledge and Use among Adolescents in Developing Countries. Studies in Family Planning, 1998; 29: 106116.

2. Abma, Driscoll A and Moore K. Young women's degree of control over first intercourse: an exploratory analysis, Family Planning Perspectives, 1998, 30: 12-18.

3. Cooksey, Elizabeth C. Outcome of adolescent first premarital pregnancies: the influence of family background. University Microfilms International: Ann Arbor, Michigan, 1988; pp: 36-40.
4. Ikamari, Lawrence, The effect of education on the timing of marriage in Kenya DemographicResearch, 2005; 12: 1-30.

5. Kiragu K and Zabin L. Contraceptive use among high school students in Kenya, International Family Planning Perspectives, 1993; 21: 108-113.

6. Ikamari, Lawrence, Factors affecting child survival in Kenya. PhD Thesis. The Demography Program. The Research School of Social Sciences. The Australian National University. Canberra: Australia, 1996; pp: 84-86.

7. Gyepi-Garbrah, B. Adolescent Fertility in sub-Sahara Africa. Chestnut Hill, MA: The Pathfinder Fund, 1985; pp: 40-45. 
8. Ilinigumugabo A. Psychosocial and Health Consequences of Adolescent Pregnancies Among Out of School Adolescent Girls in Four Rural Communities in Kenya. Center for Family Studies Research Report Series No. 1. CAFS. Kenya, 1995; pp: 20-23.

9. Ferguson A. School girl pregnancy in Kenya. Report of a Study of Discontinuation Rates and Associated Factors. Ministry of Health/GTZ Support Unit, 1988; pp: 18.

10. Njau W and Radeny S. Adolescence in Kenya. The Facts. Center for the Study of Adolescence, 1994; pp: 2-3.

11. Central Bureau of Statistics, Ministry of Health, National Council for Population and Development, Macro Inc Org. Kenya Demographic and Health Survey 2003. Macro Inc Org: Maryland, USA, 2003; pp: 7-9.

12. Bledsoe $\mathrm{CH}$ and Cohen B. Social dynamics of adolescent fertility in Sub-Saharan Africa. Population Dynamics of Sub-Saharan Africa, Washington D.C., National Academy Press, 1993; pp: 45-56.

13. Linchwe $\mathrm{K}$. The subject of traditional teaching and socialization practices on the incidence of teenage pregnancy. Report of the proceedings of a conference on teenage pregnancy in Botswana, 9-10 February 1989, National Institute of Development Research and Documentation, pp: 13-6.

14. Letamo G. Modernization and premarital dyadic formations in Botswana. Paper presented at the International Population Conference, Montreal, International Union for the Scientific Study of Population. Canada, 1993; p: 9.

15. Villarreal M. Adolescent fertility: Social cultural issues and program implications. Sustainable Development Department. FAO Women and Population Division. Food and Agricultural Organisation of the United Nations, 1998; pp: 3-8.

16. Caldwell JC, Reddy PH and Caldwell P. The causes of marriage change in South India. Population Studies, 1983; 37:343-361.

17. Castle S and Konaté, MK. The Context and Consequences of Economic Transactions Associated with Sexual Relations among Malian Adolescents. In The African Population in the 21st Century: Proceedings of the Third African Population Conference, Vol. III, Durban, 1999; 105-128.

18. Twa Twa, JM. The role of the environment on the sexual activity of school students in
Tororo and Pallisa districts of Uganda. Health Transition Review. 1997; Sup 7:7-81.

19. Djamba YK. Financial capital and premarital sexual activity in Africa: The case of Zambia. Population Research and Policy Review, 1997; 16: 243-257.

20. Moore KA Nord CW and Peterson JL. Nonvoluntary sexual activity among adolescents, Family Planning Perspectives, 1989; 21: 110-114.

21. Boyer D and Fine D. Sexual abuse as a factor in adolescent pregnancy and child maltreatment. Family Planning Perspectives. 1992; 24: 4-11 \& 19;

22. Wood $\mathrm{K}$ and Jewkes R. Violence, rape and sexual coercion: everyday love in a South African township. Gender and Development. 1997, 5:41-46.

23. Erulkar AS. Experience of Sexual Coercion Among Young People in Kenya. International Family Planning Perspectives. 2004; 30: 182-189.

24. Oladosu M. Factors Influencing Adolescent Sexual Activity in Nigeria: Analysis of the 1990 Demographic and Health Survey. Journal of Population and Social Studies. 1993; 4 : 103-119.

25. McCauley AP and Salter C. Meeting the Needs of Young Adults. Population Reports J-41. 1995.

26. Amazigo U; Silva N; Kaufman J and Obikeze DS. Sexual activity and contraceptive knowledge and use among inschool adolescents in Nigeria. International Family Planning Perspectives. 1997; 23:2833.

27. Gorgen R. Sexual behaviour and attitudes among unmarried youth in Guinea. International Family Planning Perspectives. 1998, 24:65-71;

28. Rwenge M. Sexual risk behaviours among young people in Bamenda, Cameroon. International Family Planning Perspectives. 2000, 26:118-123.

29. Afenyadu D and Lakshmi G. Adolescent Sexual and Reproductive Health Behaviour in Dodowa, Ghana. A Research Report. CEDPA: Washington DC, USA, 2003; pp: 18-22.

30. Goldscheider, C. Population, Modernization, and Social Structure. Boston: Little, Brown and Company, 1971; pp 36-39.

31. Addai I and Frank T. Structural assimilation and ethnic fertility in Ghana. Journal of Comparative Family Studies, 1999; 30:409427. 
32. Arnaldo C. Ethnicity and Marriage Patterns in Mozambique. African Population Studies. 2004; 19: 143-164.

33. Gyimah SO. Women's Educational Attainment and the Timing of Parenthood in Ghana: a Cohort Perspective. Discussion Paper No: 03-04. Population Studies Centre. University of Western Ontario, Canada, 2003; pp: 8-11.

34. United Nations,. Patterns of First Marriage: Timing and Prevalence. New York: United Nations, Department of International Economic and Social Affairs. ST/ESA/SER.R/111. 1990. pp 7-18.

35. Ewbank, DC, Hennin, R and Kekovole J. Integration of demographic and epidemiologic research on mortality in Kenya, United Nations, eds. Determinants of Mortality Change and Differentials in Developing Countries, The Five Country Case Study Project", United Nations, New York: 1986; pp: 33-79.

36. Allison P. Event History Analysis: Regression for Longitudinal Data. Sage. 1984. pp 23-34

37. Toroitich-Ruto C. The Determinants of Teenage Sexuality and their Understanding of STDs/HIV/AIDS in Kenya. African Population Studies. 1997; 12:39-50

38. Ajayi AA; Marangu, LT and Paxman JM. Adolescent Sexuality and Fertility in Kenya: A Survey of Knowledge, Perceptions, and Practices, Studies in Family Planning. 1991; 22: 205-216.

39. Gupta $\mathrm{N}$ and Mary M. Sexual Initiation among Adolescent Women and Men: Trends and Differentials in Sub-Saharan Africa. Paper prepared for the XXIV IUSSP General Population Conference, Session SB5, Adolescent Sexual and Reproductive Health' Salvador da Bahia (Brazil), 18-24 August, 2001; pp: 11-14. 